\title{
Pain extent and function in youth with physical disabilities
}

\author{
Jordi Miról-4 \\ Rocío de la Vega ${ }^{1,5}$ \\ Catarina Tomé-Pires ${ }^{1-3}$ \\ Elisabet \\ Sánchez-Rodríguez ${ }^{1-3}$ \\ Elena Castarlenas ${ }^{1-3}$ \\ Mark $\mathrm{P}$ Jensen ${ }^{5}$ \\ Joyce $M$ Engel ${ }^{6}$
}

'Unit for the Study and Treatment of Pain - ALGOS, Universitat Rovira i

Virgili, Catalonia, Spain; ${ }^{2}$ Research Center for Behavior Assessment (CRAMC), Department of Psychology, Universitat Rovira i Virgili, Catalonia, Spain; ${ }^{3}$ Institut d'Investigació Sanitària Pere Virgili, Catalonia, Spain; Universitat Rovira i Virgili, Catalonia, Spain; ${ }^{4}$ Chair in Pediatric Pain, Universitat Rovira i VirgiliFundación Grünenthal, Catalonia, Spain; ${ }^{5}$ Department of Rehabilitation Medicine, University of Washington, Seattle, WA, USA; 'Department of Occupational Science and Technology, University of Wisconsin-Milwaukee, Milwaukee, WI, USA
Correspondence: Jordi Miró Departament de Psicologia, Universitat Rovira i Virgili, Carretera de Valls s $\mathrm{n}$, 43007 Tarragona, Spain

Telephone: +349775 5I79

Email jordi.miro@urv.cat
This article was published in the following Dove Press journal:

Journal of Pain Research

5 January 2017

Number of times this article has been viewed

Background: The aim of this study was to increase our understanding of the role that spatial qualities of pain (location and extent) play in functioning, among youths with disabilities and chronic pain.

Methods: One-hundred and fifteen youths (mean age 14.4 years; $\mathrm{SD} \pm 3.3$ years) with physical disabilities and chronic pain were interviewed and were asked to provide information about pain locations and their average pain intensity in the past week, and to complete measures of pain interference, psychological function and disability. Most of the participants in this sample were males (56\%), Caucasian (68\%), and had a cerebral palsy $(34 \%)$ or muscular dystrophy (25\%) problem. Most participants did not report high levels of disability $(\bar{X}=12.7, \mathrm{SD} \pm 9.5$, range $0-60)$ or global pain intensity $(\bar{X}=3.2, \mathrm{SD} \pm 2.4$, range $0-10)$.

Results: Pain at more than one body site was experienced by $91 \%$ of participants. There were positive associations between pain extent with pain interference $(r=0.30)$ and disability $(r=0.30)$, and a negative association with psychological function $(r=-0.38)$, over and above average pain intensity. Additionally, pain intensity in the back (as opposed to other locations) was associated with more pain interference $(r=0.29)$, whereas pain intensity in the shoulders was associated with less psychological function $(r=-0.18)$, and pain intensity in the bottom or hips was associated with more disability $(r=0.29)$.

Conclusion: The findings support the need to take into account pain extent in the assessment and treatment of youths with physical disabilities and chronic pain, call our attention about the need to identify potential risk factors of pain extent, and develop and evaluate the benefits of treatments that could reduce pain extent and target pain at specific sites.

Keywords: pain extent, pediatric chronic pain, physical disability, function

\section{Background}

A growing body of evidence indicates that chronic pain is a significant problem for adults with physical disabilities. ${ }^{1-4}$ Moreover, although information from pediatric populations is scarce, research indicates that chronic pain is also a relevant health issue in youth with physical disabilities. ${ }^{5,6}$ For example, recent studies have shown that pain intensity significantly and negatively impacts the physical, emotional, and social function of youth with disabilities. ${ }^{7-9}$

The experience of pain involves more than just pain intensity; pain is a multidimensional construct that has spatial (ie, the location[s] and overall extent of perceived pain), temporal (eg, constant vs intermittent, acute vs chronic), and quality (eg, hot, electrical) characteristics. Research has shown that function, at least in adults with physical disabilities, is influenced by some of these other pain characteristics over 
and above the effects of pain intensity. For example, pain at certain locations, such as the head in adults with myotonic and facioscapulohumeral dystrophy ${ }^{10}$ or in the low back and legs in adults with spinal cord injury, ${ }^{11}$ has been demonstrated to be of greater importance than pain in other body locations in the function of these individuals. Similarly, pain extent - the total number of body areas where pain is experienced - has been found to be associated with function over and above the effects of global pain intensity in adult populations with physical disabilities and chronic pain. ${ }^{4}$ That is to say, adults who report more than one distinct pain problem or pain in more body locations are likely to also report poorer quality of life and worst function than those with pain in just one location, even when controlling for pain intensity. Similar findings have been reported in studies using samples of individuals with chronic pain as a primary presenting problem. ${ }^{12-15}$

However, the role that the spatial qualities of pain play in the function of youth populations with chronic pain is very limited. To the best of our knowledge, just one study with young people with chronic pain has addressed this issue. In this study, de la Vega et $\mathrm{al}^{7}$ reported a significant negative association between pain extent and sleep quality in a sample of 414 adolescents and young adults with a variety of chronic pain problems. Aili et $\mathrm{al}^{16}$ also reported an association between disturbed sleep and multi-site pain in a longitudinal study with a sample of individuals with low back pain. However, although they studied adults, their sample included individuals 20-59 years old, and so it is unclear how many of their sample were aged in their early twenties, and could therefore be regarded as young people.

Although it is reasonable to hypothesize that additional research in samples of youth would replicate these very preliminary results regarding the importance of pain location and pain extent, further research to establish the reliability of the findings regarding pain site and extent in youth is needed, as children should not be viewed simply as little adults. ${ }^{17}$ In fact, investigators have called for more research to study the occurrence and impact of multi-site pain in young people, as a way to identify factors that may play a role in the impact of chronic pain in youths. ${ }^{12}$ Such information is critical in order to better understand if and how adults and youth are different with respect to the key aspects that are relevant in the function of individuals with disabilities and chronic pain. If pain extent is found to contribute to the prediction of function among youth with physical disabilities and chronic pain - particularly if it does so over and above the effects of overall pain intensity - this would help us to better understand who might be at most risk of worse adjustment, and therefore who might benefit the most from treatments designed to help youth with disabilities adjust to chronic pain. Furthermore, the findings from such research would also be relevant to clinicians who design specific treatment programs, and to examine and compare the results of treatments tailored to the specific needs of the patients. For example, the hypothesis that patients with chronic localized pain in the low back would respond better to physical therapy whereas those with more extended multi-site pain problems may gain the greatest benefit from cognitive behavioral therapy, ${ }^{18}$ could be tested.

Given these considerations, the aim of this study was to increase our understanding of the role that pain extent plays in function among youth with disabilities and chronic pain. On the basis of previous research with adults, we hypothesized that pain extent would demonstrate a unique positive association with pain interference, and negative associations with psychological function and disability when controlling for average pain intensity. We also sought to examine the role that individual pain sites (eg, low back pain vs headache) might play in the associations between pain intensity and function, although we did not set a priori hypothesis regarding the importance of one pain site over another, given the paucity of previous research on this topic.

\section{Methods \\ Participants}

Participants came from a convenience sample of 115 young people with physical disabilities who had participated in a longitudinal study about the impact of chronic pain secondary to a physical disability. Although a number of articles have been published using data from this survey, ${ }^{19-22}$ none of the previous articles have addressed the study questions that are the focus of the current analyses.

In order to participate in the original study, potential participants needed to: 1) have a chronological age from 8 to 21 years; 2 ) have a diagnosis of cerebral palsy, neuromuscular disease, spinal cord injury, spina bifida, or limb deficiency (acquired or congenital); 3) be able to understand and speak English; 4) have no more than mild cognitive impairment (as measured by the modified version of the Mini-Mental State Examination); ${ }^{23}$ and 5) have the capacity for expressive communication which might have included the use of augmentative communication devices. In addition, participants for the current analyses had to report that they were experiencing a bothersome pain problem (other than one associated with a minor acute injury or illness) in the 3 months prior to the interview. We did not limit participants 
to children (ie, age $\leq 18$ years), because many pediatricians continue to treat patients that they have a history of treating, even after they become 18 years old. In fact, this study was addressed to youth, a group that normally includes individuals in their twenties.

\section{Procedures}

Further details on the study procedures can be found in the original study. ${ }^{22}$ Briefly, and most germane to the current study, participants were enrolled from different sources and with different techniques including word of mouth, mailings from clinics, and contacts with a summer camp sponsored by the Muscular Dystrophy Association (USA). Written, informed consent was obtained from all participants or their legal guardian if a minor. Following study enrollment, both youth participants and one of their parents or legal guardians were interviewed in person (when possible) or via telephone. The study was approved by the Institutional Review Board at the Children's Hospital and Regional Medical Center (Seattle, WA, USA).

\section{Measures}

The parents of the youth participants in the original study were administered a structured interview that requested information about their child's age, sex, and medical diagnosis. The youth participant interviews included questionnaires and rating scales assessing pain and disability, as well as psychological and physical functioning domains.

\section{Pain intensity}

Pain intensity was measured with a 0-10 numerical rating scale (NRS-11). Participants were asked to rate their average pain intensity in the past week by choosing a single whole number between 0 ("No pain") and 10 ("Pain as bad as could be") that best represented that pain. The NRS-11 has been found to be valid and reliable when used with young people ${ }^{24}$ even when used with children as young as 6 years of age e $^{25,26}$ and with young people with physical disabilities. ${ }^{21}$

\section{Pain site and extent}

The youth participants were also asked to indicate in which of 12 body location categories (that included 11 specific locations as well as an "other" category) they experienced pain as well as the intensity of the pain at each one of those locations. The 12 locations were: head, neck, chest, shoulders, back, arms, hands, bottom/hips, belly/pelvis, legs, feet, and "other". The number of locations were summed to create the pain extent score for each participant (possible range: $1-12$ ).

\section{Pain interference}

We used a modified version of the Brief Pain Inventory $(\mathrm{BPI})^{27,28}$ to assess pain interference. The modifications to the original 7-item questionnaire included: 1) adding three items that were specially relevant for this group of individuals with disabilities, and included items that assessed pain interference with "self-care (taking care of your daily needs)", "recreational activities", and "social activities", thus increasing the content validity of the scale; 2 ) revising the interference with "walking" item to ask about interference with "mobility (ability to get around)" which made it possible for all of the participants - including those who are not able to ambulate independently - to respond to this item; and 3) the item requesting information about "normal work" was changed to request information about "school, work, or chores", which was considered to be a more age appropriate item. Scores from the 10-item version of the BPI used in this study demonstrated excellent internal consistency, as indicated by a Cronbach's alpha of 0.90 .

\section{Psychological functioning}

The 16-item Mental Health scale (MH) of the Child Health Questionnaire (CHQ-CF87) was used to assess psychological functioning. ${ }^{29}$ The CHQ-CF87 is an 87-item questionnaire that was designed to assess psychosocial and physical wellbeing in children aged between 5 and 8 years. The CHQCF87 is scored by first computing a raw score, and then transforming it to standardized scores, with higher scores indicating better psychological functioning. The scales in the CHQ-CF87 have demonstrated adequate psychometric characteristics in a number of samples of young people with physical and psychological diagnoses. ${ }^{29}$ Scores from the $\mathrm{MH}$ scale in this study demonstrated excellent internal consistency, as indicated by a Cronbach's alpha of 0.88 .

\section{Disability}

Disability was assessed using the 15-item Functional Disability Inventory (FDI). ${ }^{30}$ Respondents were asked to rate how difficult it was for them to engage in regular activities in the last few days on a 0 ("No trouble") to 4 ("Impossible") scale. ${ }^{31}$ The FDI was developed specifically to assess disability in children, and has demonstrated excellent reliability and validity properties. ${ }^{30,32}$ Higher scores indicate more disability (possible range: 0 to 60 ). In the current sample, the internal consistency (Cronbach's alpha) of the disability score was 0.81 .

\section{Statistical analyses}

We first computed descriptive statistics for the demographic and study variables to describe the sample. Next, 
we examined the distributions of the study variables and computed variance inflation factors (VIF) for the study predictors to ensure that they met assumptions for the planned regression analyses. ${ }^{33}$ We also computed zero-order correlation coefficients between pain extent and the criterion variables. Finally, we performed three regression analyses - one for each of the criterion variables of pain interference, psychological function, and disability - to determine if pain extent and pain intensity at specific sites explained unique variance in the criterion variables. We entered average pain intensity in step 1 as a control variable. We then entered pain extent in step 2 in order to determine if it accounted for significant variance in the criterion variables, over and above pain intensity. In step 3 , we entered pain intensity at each of 12 pain sites, stepwise, to determine if pain intensity at any one (or more) specific site(s) contributed to the prediction of the criterion variables when controlling for pain intensity and pain extent.

\section{Results}

\section{Sample and study variables description}

The majority of the study sample were White/Caucasian $(68 \%)$ and males (56\%). The average age of the participants when they completed the survey was 14.4 years $(\mathrm{SD} \pm 3.3$; median 13 years; range 8-21 years). Sixteen (14\%) of the participants were prepubescent (age $\leq 10$ years), $32(28 \%)$ were 11-12 years old, 36 (31\%) were $13-15$ years old, 31 (27\%) were 16-18 years old, and 14 (12\%) were 19-21 years old. Almost all participants experienced pain at more than one body site (91\%). Additional descriptive information about the study sample and variables in the study are presented in Tables 1 and 2 .

\section{Assumptions testing}

All of the distributions of the study variables were adequately normal for the planned regression analyses (skewness range -1.05 to 1.46 ; kurtosis range, -1.07 to 1.32 ). In addition, all of the variance inflation factor statistics were all well below the standard cutoff value of 10 (range 1.07 to 1.42), indicating that multicollinearity would not bias the findings. ${ }^{33}$

\section{Zero-order correlations between pain extent and pain interference, psychological functioning, and disability}

The zero-order associations between pain extent and the study criterion variables (pain interference, psychological functioning, and disability) were $0.47,-0.49$, and 0.36 (all $p<0.001$ ), respectively, indicating moderate-to-large associations.
Table I Description of the study sample $(\mathrm{N}=\mid$ I5)

\begin{tabular}{|c|c|c|c|c|}
\hline Variable & Percent & $n$ & Mean (SD) & Range \\
\hline Age, years & & 115 & I4.4 (3.3) & $8-21$ \\
\hline \multicolumn{5}{|l|}{ Sex } \\
\hline Boys & 56 & 65 & & \\
\hline Girls & 44 & 50 & & \\
\hline \multicolumn{5}{|l|}{ Ethnicity/race ${ }^{\mathrm{a}}$} \\
\hline Caucasian & 68 & 78 & & \\
\hline Asian & 11 & 11 & & \\
\hline African-American & 3 & 3 & & \\
\hline American Indian & 3 & 3 & & \\
\hline Hispanic/Chicano & 4 & 4 & & \\
\hline Other & I & I & & \\
\hline \multicolumn{5}{|l|}{ Diagnosis } \\
\hline Cerebral palsy & 34 & 39 & & \\
\hline Amputation & 3 & 4 & & \\
\hline Limb deficiency & 2 & 3 & & \\
\hline Spina bifida & 23 & 27 & & \\
\hline $\begin{array}{l}\text { Muscular } \\
\text { dystrophy }\end{array}$ & 25 & 29 & & \\
\hline Spinal cord injury & 10 & 11 & & \\
\hline $\begin{array}{l}\text { Amputation and } \\
\text { limb deficiency }\end{array}$ & 2 & 2 & & \\
\hline \multicolumn{5}{|l|}{ Number of pain } \\
\hline \multicolumn{5}{|l|}{ locations } \\
\hline I & 9 & 11 & & \\
\hline 2 & 12 & 14 & & \\
\hline 3 & 15 & 17 & & \\
\hline 4 & 14 & 16 & & \\
\hline 5 & 12 & 14 & & \\
\hline 6 & 12 & 14 & & \\
\hline 7 & II & 13 & & \\
\hline 8 & 4 & 5 & & \\
\hline 9 & 4 & 4 & & \\
\hline 10 & 5 & 6 & & \\
\hline 11 & I & I & & \\
\hline
\end{tabular}

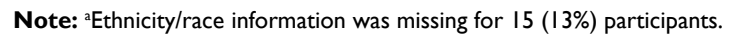
Abbreviation: SD, standard deviation.

\section{Effects of pain extent and pain site on pain interference, psychological functioning, and disability}

Pain interference: in the regression analysis predicting pain interference, overall pain intensity in the previous week explained $38 \%$ of the variance (Table 3 ). After controlling for overall pain intensity, higher pain extent accounted for an additional $8 \%$ of the variance in the criterion, whereas pain intensity experienced in the back predicted an additional statistically significant $2 \%$ of the variance.

Psychological function: in the regression analysis predicting psychological functioning, overall pain intensity in the previous week explained $20 \%$ of the variance (Table 4). After controlling for overall pain intensity, higher pain extent accounted for an additional 14\% of the variance in the criterion, whereas pain intensity experienced 
Table 2 Mean and standard deviations for study measures $(\mathrm{N}=\mid \mathrm{I})$

\begin{tabular}{ll}
\hline & Mean (SD) \\
\hline Pain extent (I-I2) & $4.6(2.5)$ \\
Global average pain intensity (0-I0 NRS, 0-10) & $3.2(2.4)$ \\
Pain interference (BPI, 0-I0) & $1.9(1.8)$ \\
Psychological functioning (CHQ-CF87; MH, 0-100) & $73.3(15.5)$ \\
Disability (FDI; 0-60) & $12.7(9.5)$ \\
Average pain intensity at each site (0-10) & \\
Head & $2.3(2.4)$ \\
Neck & $1.6(2.3)$ \\
Chest & $1.0(2.2)$ \\
Shoulders & $1.7(2.6)$ \\
Back & $3.1(2.9)$ \\
Arms & $1.1(2.0)$ \\
Hands & $0.9(2.0)$ \\
Bottom/hips & $1.8(2.5)$ \\
Belly/pelvis & $1.0(2.3)$ \\
Legs & $3.3(3.1)$ \\
Feet & $2.0(2.9)$ \\
Other & $0.6(2.0)$ \\
\hline
\end{tabular}

Notes: ${ }^{\mathrm{a}} \mathrm{For}$ all $(\mathrm{N}=115)$ study participants, including those who reported no pain at the site. $0-10$ NRS, where $0=$ no pain and $10=$ pain as bad as could be.

Abbreviation: SD, standard deviation; NRS, numerical rating scale; BPI, modified brief pain inventory pain interference scale; MH, Mental Health scale of the Child Health Questionnaire; FDI, Functional Disability Inventory; CHQ-CF87, Child Health Questionaire.

Table 3 Multiple regression analyses predicting pain interference

\begin{tabular}{lllll}
\hline Steps and variables & Total $\boldsymbol{R}^{2}$ & $\boldsymbol{R}^{2}$ change & $\boldsymbol{F}$ change & Beta \\
\hline $\begin{array}{l}\text { I. Average pain intensity } \\
\quad 0.38\end{array}$ & 0.38 & $69.95^{* *}$ & 0.36 \\
$\begin{array}{l}\text { in previous week } \\
\text { 2. Pain extent }\end{array}$ & 0.46 & 0.08 & $16.42^{* *}$ & 0.30 \\
3. Back pain intensity & 0.49 & 0.02 & $5.33^{*}$ & 0.29 \\
\hline
\end{tabular}

Note: $* p<0.05, * * p<0.001$.

Table 4 Multiple regression analyses predicting psychological functioning

\begin{tabular}{lllll}
\hline Steps and variables & Total $\boldsymbol{R}^{2}$ & $\boldsymbol{R}^{2}$ change & $\boldsymbol{F}$ change & Beta \\
\hline $\begin{array}{l}\text { I. Average pain intensity } \\
\quad \text { in previous week }\end{array}$ & 0.21 & 0.21 & $30.15^{* *}$ & -0.46 \\
$\begin{array}{l}\text { 2. Pain extent } \\
\text { 3. Shoulders pain intensity }\end{array}$ & 0.35 & 0.14 & $22.59^{* *}$ & -0.38 \\
\hline
\end{tabular}

Note: ${ }^{*} p<0.05,{ }^{* *} p<0.001$.

in the shoulders predicted an additional and statistically significant $2 \%$.

Disability: in the regression analysis predicting disability, overall pain intensity in the previous week explained $12 \%$ of the variance (Table 5). After controlling for overall pain intensity, higher pain extent accounted for an additional $8 \%$ of the variance in the criterion. Pain intensity experienced in the bottom/hips predicted an additional $6 \%$ of the variance, over and above the effects of average pain intensity and pain extent.
Table 5 Multiple regression analyses predicting disability

\begin{tabular}{lllll}
\hline Steps and variables & Total $\boldsymbol{R}^{2}$ & $\boldsymbol{R}^{2}$ change & $\boldsymbol{F}$ change & Beta \\
\hline $\begin{array}{l}\text { I. Average pain intensity } \\
\text { in previous week }\end{array}$ & 0.13 & 0.13 & $16.27^{* *}$ & 0.36 \\
$\begin{array}{l}\text { 2. Pain extent } \\
\text { 3. Bottom/hips pain }\end{array}$ & 0.21 & 0.08 & $11.33^{*}$ & 0.30 \\
$\quad$ intensity & & 0.06 & $8.73^{*}$ & 0.29 \\
\hline Note: ${ }^{*} p<0.05, * * p<0.001$. & & & & \\
\hline
\end{tabular}

\section{Discussion}

This study documents, for the first time, the relationship between pain extent and function in a sample of young people with physical disabilities and chronic pain. Consistent with the study hypothesis, pain extent showed positive associations with pain interference and disability, and a negative association with psychological function, over and above average pain intensity. In addition, pain intensity in the back (as opposed to other locations) was associated with more pain interference, whereas pain intensity in the shoulders was associated with less psychological function, and pain intensity in the bottom or hips was associated with more disability.

The results with respect to pain extent are consistent with those from the only study available that has examined the relationship between pain extent and function in young people with chronic pain as a primary presenting problem ${ }^{7}$ and from a number of studies with adults with chronic pain. ${ }^{18,34-37} \mathrm{As}$ a group, these findings support the generalizability of the importance of pain extent over and above the effects of pain intensity to the adjustment of people with chronic pain across age groups and pain types; it does not just matter how much a person hurts, but also over how many body areas one hurts. This finding supports the need to take into account pain extent in the assessment and treatment of individuals with chronic pain, whether pain is a primary presenting complaint or it is a secondary problem related to a physical disability.

In this study, almost all (91\%) of the participants reported having pain at more than one distinct location. This finding is consistent with a number of studies with young people and adults with chronic pain indicating that the majority of individuals with chronic pain experience pain at more than just a single site. ${ }^{38-41}$ This finding of high rates of multi-sited pain may be due to the fact that having pain in certain areas increases the likelihood of having pain in some other places. For example, Smith et a $\mathrm{l}^{42}$ found that having chronic pain anywhere in the body (other than in the back) at an initial assessment was a strong predictor of the development of chronic back pain 4 years later. On the other hand, in their 14-year prospective study, Kamaleri et al ${ }^{12}$ found that although the number of pain sites show a slight increase over time on 
average, the number of areas of pain people present with is fairly stable. Therefore, and given the general stability of the number of pain sites over time, once the number of pain sites that a person has is determined and the modifiable risk factors for having more than one pain problem are identified, specific treatment programs to reduce the number of pain sites or prevent pain from spreading can be developed as one possible way to improve adjustment to chronic pain, even if the overall magnitude or intensity of the pain is not reduced. Therefore, an important next step, then, is to identify these modifiable factors that could be potential treatment targets. Viable candidates include physical inactivity and guarding, ${ }^{43-45}$ pacing difficulties, ${ }^{46,47}$ and pain-related beliefs. ${ }^{48-50}$

The exploratory analyses examining the relative importance of specific pain sites showed that the pain sites that are most closely associated with patient function differ depending on the outcome variable studied. Although some of these relationships are consistent with previous research ${ }^{4,11}$ and make intuitive sense (eg, it seems reasonable that pain in the back is the site that is most closely associated with pain interference, because the muscles in the back are involved in almost all actions in which the upper body is involved and many of those in which the activity of the lower body is involved), the possible reasons for the importance of other locations to patient function are less clear. It is difficult to identify a reason as to why pain intensity in the shoulders may be more closely associated with lower psychological function than pain at other sites, for example. Future studies are needed to determine which of the current findings related to specific sites replicate before identifying the potential reasons for the associations found. As more is learned about the relative importance of one or more specific pain site over others, treatment programs could potentially be developed to help patients better manage pain at specific sites, as a potential strategy of maximizing function.

\section{Limitations}

A number of limitations of this study should be considered when interpreting the results. First, the sample included children who had five different disability diagnoses, and the number of participants in each diagnostic group differed. Thus, although the overall sample size of the study was relatively large and appropriate for the analyses conducted, the sample size was not large enough to allow us to determine if there were any differences in the importance of pain extent or pain at specific sites as a function of diagnosis. The possibility that the associations found difference between diagnostic groups will need to be examined in studies with larger sample sizes. Second, our sample of participants was one of convenience; we cannot be certain therefore that the sample is representative of the populations of youth with pain who have the diagnoses studied. Therefore, replication of the current findings in additional samples of youths with physical disabilities are needed to help establish the reliability and generalizability of these findings.

\section{Conclusion}

Despite the study's limitations, the findings provide important additional information on the relationships between pain and function in youth with physical disabilities and chronic pain. The findings support the need to take into account pain extent in the assessment and treatment of these young people, call our attention about the need to identify potential risk factors of pain extent, and develop and evaluate the benefits of treatments that are designed to reduce pain extent and target pain at specific sites.

\section{Acknowledgments}

Support for the study upon which the findings reported here are based was provided by Grant P01 ND/NS 33988 from the National Institute of Child Health and Human Development and the National Institute of Neurological Disorders and Stroke, National Institutes of Health.

Financial support for this work was provided, in part, by grants from Obra Social de Caixabank, Universitat Rovira i Virgili (PFR Program), Spanish Ministry of Economy and Competitiveness (MINECO; PSI2012-32471, PSI201570966-P). Rocío de la Vega's work is supported by a Beatriu de Pinós Postdoctoral Fellowship (2014 BP-A 00009) granted by the Agency for Administration of University and Research Grants (AGAUR). Rocío de la Vega's travel is supported by the grant R2B (grant for the enhancement of knowledge) by the Universitat Rovira i Virgili. Elena Castarlenas' work is supported by grant PSI2014-60180-JIN of the Spanish Ministry of Economy and Competitiveness. Jordi Miró's work is also supported by the Institució Catalana de Recerca $i$ Estudis Avançats (ICREA-Acadèmia), and Fundación Grünenthal.

\section{Disclosure}

The authors report no conflicts of interest in this work.

\section{References}

1. Carter GT, Miró J, Ted Abresch R, El-Abassi R, Jensen MP . Disease burden in neuromuscular disease: the role of chronic pain. Phys Med Rehabil Clin NAm. 2012 Aug;23(3):719-729. 
2. Ehde DM, Jensen MP, Engel JM, Turner JA, Hoffman AJ, Cardenas DD. Chronic pain secondary to disability: a review. Clin J Pain. 2003; 19(1):3-17.

3. Jensen MP, Moore MR, Bockow TB, Ehde DM, Engel JM. Psychosocial factors and adjustment to chronic pain in persons with physical disabilities: a systematic review. Arch Phys Med Rehabil. 2011;92(1):146-160.

4. Miró J, Gertz KJ, Carter GT, Jensen MP. Chronic pain in neuromuscular disease: pain site and intensity differentially impacts function. Phys Med Rehabil Clin N Am. 2012;23(4):895-902.

5. Engel JM, Kartin D. Pain in youth: a primer for current practice. Crit Rev Phys Rehabil Med. 2004;16(1):53-76.

6. Belew JL, Barney CC, Schwantes SA, Tibboel D, Valkenburg AJ SF. Pain in children with intellectual or developmental disabilities. In: PJ McGrath, BJ Stevens, SM Walker, WT Zempsky, editors. Oxford texbook of pediatric pain. Oxford University Press. 2014:147-56.

7. de la Vega R, Racine M, Sánchez-Rodríguez R, et al. Pain extent, pain intensity, and sleep quality in adolescents and young adults. Pain Med. 2016;17(11):1971-1977.

8. Houlihan CM, O'Donnell M, Conaway M, Stevenson RD. Bodily pain and health-related quality of life in children with cerebral palsy. Dev Med Child Neurol. 2004;46(05):305-310.

9. van der Putten A, Vlaskamp C. Pain assessment in people with profound intellectual and multiple disabilities; a pilot study into the use of the Pain Behaviour Checklist in everyday practice. Res Dev Disabil. 2011;32(5):1677-1684.

10. Miró J, Gertz KJ, Carter GT, Jensen MP. Pain location and intensity impacts function in persons with myotonic dystrophy type 1 and facioscapulohumeral dystrophy with chronic pain. Muscle Nerve. 2014;49(6):900-905.

11. Miró J, Gertz KJ, Carter GT, Jensen MP. Pain location and functioning in persons with spinal cord injury. PM R. 2014;6(8):690-697.

12. Kamaleri Y, Natvig B, Ihlebaek CM, Benth JS, Bruusgaard D. Change in the number of musculoskeletal pain sites: A 14-year prospective study. Pain. 2009;141(1-2):25-30.

13. Neupane S, Miranda H, Virtanen P, Siukola A, Nygård CH. Multi-site pain and work ability among an industrial population. Occup Med (Lond). 2011;61(8):563-569.

14. Valentin GH, Pilegaard MS, Vaegter HB, et al. Prognostic factors for disability and sick leave in patients with subacute non-malignant pain: a systematic review of cohort studies. BMJ Open. 2016;6(1):e007616.

15. Natvig B, Bruusgaard D, Eriksen W. Localized low back pain and low back pain as part of widespread musculoskeletal pain: Two different disorders? A cross-sectional population study. J Rehabil Med. 2001;33(1):21-25

16. Aili K, Nyman T, Svartengren M, Hillert L. Sleep as a predictive factor for the onset and resolution of multi-site pain: A 5-year prospective study. Eur J Pain. 2015;19(3):341-349.

17. Mcgrath PA. Children - Not Simply “Little Adults". IASP Press. 2005;433-446.

18. Carnes D, Parsons S, Ashby D, et al. Chronic musculoskeletal pain rarely presents in a single body site: Results from a UK population study. Rheumatology. 2007;46(7):1168-1170.

19. Engel JM, Kartin D, Carter GT, Jensen MP, Jaffe KM. Pain in youths with neuromuscular disease. Am J Hosp Palliat Care. 2009;26(5):405-12.

20. Engel JM, Wilson S, Tran ST, Jensen MP , Ciol MA. Pain catastrophizing in youths with physical disabilities and chronic pain. $J$ Pediatr Psychol. 2013;38(2):192-201.

21. Miró J, Castarlenas E, de la Vega R, et al. Validity of three rating scales to measure pain intensity among youths and young adults with physical disabilities. Eur J Pain. 2016;20(1):130-137.

22. Wilson S, Washington L, Engel JM, Ciol MA, Jensen M. Perceived social support, psychological adjustment, and functional ability in youth with disabilities. Rehabil Psychol. 2006;51:322-330.

23. Folstein MF, Folstein SE, McHugh PR. "Mini-mental state". A practical method for grading the cognitive state of patients for the clinician. J Psychiatr Res. 1975;12(3):189-918.
24. Miró J, Castarlenas E, Huguet A. Evidence for the use of a numerical rating scale to assess the intensity of pediatric pain. Eur J Pain. 2009; 13(10):1089-1095.

25. Castarlenas E, Miró J, Sánchez-Rodríguez E. Is the verbal numerical rating scale a valid tool for assessing pain intensity in children below 8 years of age? J Pain. 2013;14(3):297-304.

26. Sánchez-Rodríguez E, Miró J, Castarlenas E. A comparison of four self-report scales of pain intensity in 6- to 8-year-old children. Pain. 2012;153(8):1715-1719.

27. Cleeland CS. The Brief Pain Inventory: user guide. Houston: The University of Texas M. D. Anderson Cancer Center. 2009.

28. Cleeland CS, Ryan KM. Pain assessment: global use of the Brief Pain Inventory. Ann Acad Med Singapore. 1994;23(2):129-138.

29. Landgraf JM, Abetz I, Ware JE. Child Health Questionnaire (CHQ). A user's manual. Boston: The Health Institute; 1996.

30. Claar RL, Walker LS. Functional assessment of pediatric pain patients: psychometric properties of the functional disability inventory. Pain. 2006; 121:77-84.

31. Walker LS, Greene JW. The functional disability inventory: measuring a neglected dimension of child health status. J Pediatr Psychol. 1991;16(1):39-58.

32. Kashikar-Zuck S, Flowers SR, Claar RL, et al. Clinical utility and validity of the Functional Disability Inventory among a multicenter sample of youth with chronic pain. Pain. 2011;152(7):1600-1607.

33. Tabachnick BG, Fidell LS. Using Multivariate Statistics. 6th Ed. Harlow: Pearson; 1996.

34. Gureje O, Von Korff M, Kola L, et al. The relation between multiple pains and mental disorders: results from the World Mental Health Surveys. Pain. 2008;135(1-2):82-91

35. Haukka E, Kaila-Kangas L, Ojajärvi A, et al. Pain in multiple sites and sickness absence trajectories: a prospective study among Finns. Pain. 2013;154(2):306-312.

36. Larsson B, Sund AM. Emotional/behavioural, social correlates and oneyear predictors of frequent pains among early adolescents: influences of pain characteristics. Eur J Pain. 2007;11(1):57-65.

37. Wolfe F, Michaud K. Predicting depression in rheumatoid arthritis: the signal importance of pain extent and fatigue, and comorbidity. Arthritis Care Res. 2009;61(5):667-673.

38. Aggarwal VR, McBeth J, Zakrzewska JM, Lunt M, Macfarlane GJ The epidemiology of chronic syndromes that are frequently unexplained: do they have common associated factors? Int J Epidemiol. 20061;35(2):468-476.

39. Huguet A, Miró J. The severity of chronic pediatric pain: an epidemiological study. J Pain. 2008;9(3):226-236.

40. Kamaleri Y, Natvig B, Ihlebaek CM, Bruusgaard D. Localized or widespread musculoskeletal pain: Does it matter? Pain. 2008;138(1):41-46.

41. van Hecke O, Torrance N, Smith BH. Chronic pain epidemiology and its clinical relevance. Br J Anaesth. 2013;111(1):13-18.

42. Smith,BH, Elliott AM, Hannaford PC, Chambers WA, Smith WC. Factors related to the onset and persistence of chronic back pain in the community: results from a general population follow-up study. Spine. 2004;29(9):1032-1040.

43. Fordyce WE. Behavioral methods for chronic pain and illness. St. Louis: Mosby; 1976.

44. Main CJ, Keefe FJ, Jensen MP, Vlaeyen JWS, Vowles KE. Fordyce's Behavioral Methods for Chronic Pain and Illness. Philadelphia: Wolters Kluwer; 2014.

45. Slifer KJ, Amari A, Ward CM. Operant treatment. In: PJ McGrath, BJ Stevens, SM Walker, WT Zempsky, editors. Oxford texbook of pediatric pain. Oxford: University Press; 2014; 531-542.

46. Nielson WR, Jensen MP, Karsdorp PA, Vlaeyen JW. Activity pacing in chronic pain: concepts, evidence, and future directions. Clin J Pain. 2013;29(5):461-468.

47. Nielson WR, Jensen MP, Karsdorp PA, Vlaeyen JW. A content analysis of activity pacing in chronic pain: what are we measuring and why? Clin J Pain. 2014;30(7):639-645. 
48. Jensen MP, Turner JA, Romano JM. Changes after multidisciplinary pain treatment in patient pain beliefs and coping are associated with concurrent changes in patient functioning. Pain. 2007;131(1-2):38-47.

49. Miró J, Huguet A, Jensen MP. Pain beliefs predict pain intensity and pain status in children: usefulness of the pediatric version of the survey of pain attitudes. Pain Med. 2014;15(6):887-897.
50. Nieto R, Raichle KA, Jensen MP, Miró J. Changes in pain-related beliefs, coping, and catastrophizing predict changes in pain intensity, pain interference, and psychological functioning in individuals with myotonic muscular dystrophy and facioscapulohumeral dystrophy. Clin J Pain. 2012;28(1):47-54.

\section{Publish your work in this journal}

The Journal of Pain Research is an international, peer reviewed, open access, online journal that welcomes laboratory and clinical findings in the fields of pain research and the prevention and management of pain. Original research, reviews, symposium reports, hypothesis formation and commentaries are all considered for publication. 